\title{
Impact of ICT on Environment and Green Computing
}

\author{
Harjit Singh \\ Assistant Professor, Department of Computer Science, Punjabi University, Neighbourhood Campus, Dehla Seehan (Sangrur), Punjab, India
}

\begin{abstract}
Whole world is facing environmental crisis and it is the most discussed topic nowadays. Earth's environment is being deteriorated with the human behavior. We as human are enjoying luxury and comfortable life that is all because of Technology. More technology means more the economic growth and higher the living standard of the people. Technologically advanced countries are more economically strong than others. Among all that technology, Information and Communication Technology (ICT) is the fastest growing technology. ICT played a major role in the economic growth of a country. It is so beneficial that it became an unavoidable part of each and every field. But on the other side, ICT may have important negative impacts on the environment. Careless use of ICT, increases problems related to environment. Substantial material, water and electricity consumption by the IT industry is also a major reason to the environmental problems. This paper is an attempt to explore the environmental related problems pertaining to information technology.
\end{abstract}

Keywords: ICT, Environment, Environment Problems, Environment deterioration, Eco-friendly, E-waste, Green ICT, Negative Impact of ICT, Positive Impact of ICT, IT industry, Consumption, Non-degradable wastage.

\section{Introduction}

We are human beings are we consider that we are the controlling species on the earth and we have the right to control other species as well as enjoy all the resources on the earth like sunlight, forests, water, lands etc. But it is not like that. Actually, we are part of this environment like other species and resources are. Each specie has a specific range of using the resources from the earth. But human beings are consuming more resources than they actually need which directly or indirectly produces more wastage. We need new things everyday without any good reason even if our old things are working very well. Other species have natural ways of exchange, but we use money to exchange or purchase things. Unfortunately the distribution of money is not even. People having more money than the need uses more resources than the need and hence produce more wastage than the environment can degrade. With this greed and advancement of technology, we also produce non-degradable products. And this non-degradable material is the major environment problem.

Now we have huge buildings to live, long roads and luxury cars to travel, big aero planes to visit other sides of the earth in a shortest possible time. And now we are at such a state that we find ourselves disabled without technology. The widespread technology is Information and Communication Technology. It has its own risks to environment.

Technology is changing so fast that every day we are having exciting and new models of mobile phones, computers and laptops and every kind of electronics with new functionalities. Communication is made so easy that we can talk to our friends and relatives through mobile phones and can see them while talking though web cam. Also we can use voice chats and emails to communicate with them. Due to globalization and ease of doing work there are just no boundaries left for doing business. One being living in India can conduct business in Australia. Fans and air-conditioners are used to protect from the outside heat. There is a long list of benefits enjoyed by human beings now-a-days goes on and on and can never end so do the impacts on environment caused by these activities.

Today, the increased technology needs in everything we use has resulted in increased number of IT companies which is economical very good and has created lots of job opportunities worldwide but the other side of mirror is darker as it has led to increased carbon emissions in the atmosphere. Not only factories and agriculture are responsible for Carbon emissions, but IT Industry, telecommunication, hospitals, film industry, or any type of business is responsible for the release of greenhouse gases in atmosphere and other problems related to the environment. There is no single sector that can be excluded from being responsible towards environment and so is the case with Information Technology. The need for the instant access to the information has resulted in the growing demand of hardware, software and IT services.

IT operations are not only crucial aspects of the IT organizations alone but almost every kind of organizations depends on information systems to run their businesses. Where Internet is needed by all kind of businesses, individuals around the world and that too for $24 / 7$ and the availability of data and information makes the server's availability mandatory. In other words business continuity is one of the main concerns that make the information systems and their availability very important. If information system gets down it can partially or completely shut down the operations of the organization and this makes the power usage by the IT operations a first and foremost issue as its impact is significantly large and this is how it is directly deteriorating earth's atmosphere.

\section{Volume 4 Issue 12, December 2015}




\section{International Journal of Science and Research (IJSR) \\ ISSN (Online): 2319-7064}

Index Copernicus Value (2013): 6.14 | Impact Factor (2014): 5.611

\section{Impact of ICT}

To evaluate the environmental impact of a product, its life cycle can be divided into three phases: the production, the use and the end-of-life. The impacts on the environment of ICT can be separated in three categories (Radermacher, 1999; Berkhout and Hertin, 2001; Fichter, 2001; Arnfalk, 2002):

- Direct effects: energy consumption, use of resources, emissions and pollution caused by the production, trade and transport of goods, and by the disposal and recycling at the end of the devices' life cycle use.

- Indirect effects: changes in the economic structure, changes of the production processes, trade and transportation systems. The most important effects in this context are dematerialization, virtualization and immobilization of goods.

- Effect on the people's lifestyle and social values.

We will discuss separately the negative and positive impacts of ICT.

\subsection{Negative impact of ICT}

Direct environmental impacts come from ICT manufacturing and services producing firms and related intermediate goods producers, and from final consumers and users of ICT products. ICT manufacturers affect the natural environment through ICT goods and services production and through associated operations. For example production operations for operating infrastructures, building functions, vehicle fleets and logistics can have more or less environmental impacts.

The technologies used in daily life utilize more resources and power than they need to. And wastage of resources and power for manufacturing them can create a chaos. Some of the points where technology is responsible to harm the environment:

- Pollution - Water, air, soil and noise pollution is caused by production and utilization of technology.

- Consuming resources - Non-renewable resources and precious metals like gold are used by industry to make technology. Coal is consumed to produce the electricity to use technology. Some renewable resources such as trees and water are becoming contaminated or they are being consumed faster than they are able to renew themselves because of technology. According to (Hilty and Ruddy, 2000 ), only $2 \%$ of the used materials compose the computer in the production phase and $98 \%$ are wastes.

- Waste - Manufacturing technology creates huge amounts of waste material and when used computers and electronic devices are thrown out when they break or become outdated, it becomes significantly dangerous for our environment. Thrown electronic devices are called "technotrash" and they contain all sorts of harmful materials that are very dangerous for the environment. They are required to be disposed of through special methods

- Disrupting ecology - Clearing land where animals used to live to build factories and allowing pollution to contaminate the food chain can greatly affect the environment's natural cycles.

- Health hazards - Toxic materials used can harm human health and can cause cancer. Technology addiction can lead to other health related problems like obesity and carpal tunnel syndrome.

There are about 2 billion PCs in use worldwide. It contributes to the emission of green house gases. As reported by Gartner PCs and monitor contribute to $39 \%$ of total ICT contribution in carbon emissions which is equal to 49.3 million cars on the road.

(Wikipedia, 27 July 2010) A typical PC consumes half of the power for its operations and waste the rest half as "HEAT" and for the typical server $30 \%$ to $40 \%$ of the energy consumed is wasted. Now this surely is not a small amount when in the organization thousands of the PC, Laptops are running and data centers in which number of servers are operating. The heat emitted as waste arises the demand of air-conditioning which in turn increase the power requirements and the bill associated with it. The more equipment you have that is less efficient the more heat it will generate and that means that more electricity will be required to cool those equipments. May be the facts and figures above are surprising but the more surprising thing is that this heat can be utilized as well. As Engineers we should find the opportunities in every problem. The Switzerland Company utilized the heat generated from their data centers to heat the nearby swimming pool; now this is called resource utilization. The other reason is improper power management. Improper power management is utilizing the power more than it is required. It can be due to human negligence of utilizing the power more than their requirements e.g. not switching off the lights, AC, computers and laptops when they are not using them and it can be due to the inefficient design of the electronic devices .e.g. consuming a lot of power to operate or not able to recognize when the system is in idle state.

(Sustainable Information Technology, 2005)UN Studies revealed that a single Computer Screen Manufacturing consumes 530 pounds of fossil fuels, 48 pounds of chemicals and 3000 pounds of water. More than 3000 pounds material is consumed in manufacturing process. Typically, manufacturing process of computers uses cadmium, lead, mercury and many other toxic substances. Lead is one of the most toxic substances and about 4 to 8 pounds of lead is used in each computer display. Environment issues related to lead are many. It can damage blood and nervous system of humans.

"Data center servers consume 50 times the energy used per square foot in an office" says Mark Bramfitt, Principal program manager at PG\&E. To keep servers at the right temperature, companies mainly rely on air-conditioning equipments. The more powerful the machine, the more cool air needed to keep it from overheating.

Faster processors used for servers use extra power and their waste heat increases environment temperature for which air conditioning is required. The waste heat is also responsible

\section{Volume 4 Issue 12, December 2015}




\section{International Journal of Science and Research (IJSR) \\ ISSN (Online): 2319-7064}

Index Copernicus Value (2013): 6.14 | Impact Factor (2014): 5.611

for reliability problems, because processors can crash at higher temperatures.

Carbon emissions (mostly carbon dioxide and carbon monoxide) are greenhouse gasses that are emitted by people. Greenhouse gasses in the atmosphere trap and reflect heat and radiation back to the earth's surface. It is considered that over the last century, there is a great increase in the amount of greenhouse gasses in the atmosphere due to carbon emissions. They are contributing to global warming.

Carbon emissions get discharged into the atmosphere from vehicles like cars, air planes and things like factories and power plants. They are also released by human when electricity is generated from burning fossil fuels.

Technotrash is any broken or outdated electronic or electrical device which becomes e-waste and is the most rapidlygrowing type of waste now-a-days.

If we just throw away e-waste with the ordinary trash, it typically reaches in a landfill in most cases. These electronic devices contain non-biodegradable materials and heavy metals and toxic substances like cadmium, mercury and lead. After some time these toxic substances can leak into the ground resulting contamination of water that we drink, the plants that we eat and the animals that stay around us.

These toxic substances can cause nausea, vomiting, diarrhea, cancer and much more. By drinking and eating contaminated water and food, these toxins can build up in the body. By eating contaminated animals, we are getting a double dose of toxins.

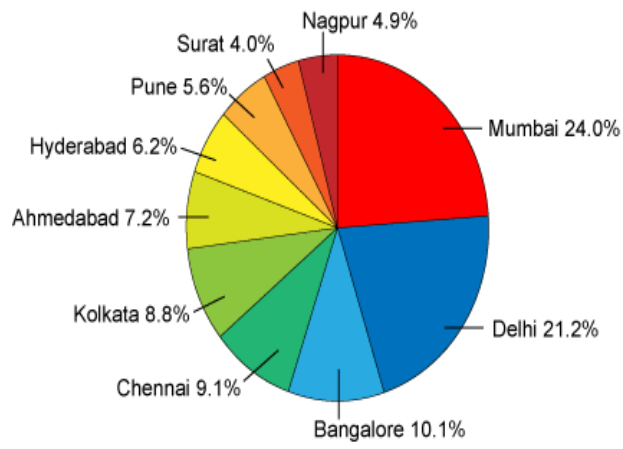

City-wise E-waste Generation in India (Tonnes/year)

If ICT products make demand for other products then this is called Induction effect. For example, more efficient printers stimulate demand for high quality paper, increasing pressure on forest and paper-making resources, even if direct resource use is decreased in the production and operation of printers.

When ICT products are embedded in non-ICT products, degradation can occur which can result difficulties in disposal management. For example, smart tags used in car tires, cardboards and bottles need particular recycling methods that are more difficult and add to the pollution pack.
According to the records of Computer Industry Almanac Inc, in 2012, the Number of PCs In-Use in India were 57 million as shown in Table 1:

Table 1: PCs In-Use in 2012

\begin{tabular}{|c|c|c|c|}
\hline Rank & Country & $\begin{array}{c}\text { PCs In-Use (in } \\
\text { Millions) }\end{array}$ & $\begin{array}{c}\text { Sharing \% of } \\
\text { World Total }\end{array}$ \\
\hline 1 & U.S. & 310.6 & 19.4 \\
\hline 2 & China & 195.1 & 12.2 \\
\hline 3 & Japan & 98.1 & 6.12 \\
\hline 4 & Germany & 71.5 & 4.47 \\
\hline 5 & India & 57 & 3.56 \\
\hline 6 & UK & 54.5 & 3.41 \\
\hline 7 & Russia & 53.5 & 3.34 \\
\hline 8 & France & 53.5 & 3.34 \\
\hline 9 & Brazil & 48.1 & 3.01 \\
\hline 10 & Italy & 44.7 & 2.79 \\
\hline \multicolumn{4}{|c|}{ Source: Computer Industry Almanac Inc. } \\
(http://www.c-i-a.com/pr02012012.htm)
\end{tabular}

Now in 2015, the status of Indian IT is:

INDIAN IT IN NUMBERS

(Source: India Tech Online, Updated December 7, 2015)

(http://www.indiatechonline.com/snapshot.php)

Total no. of phone subscriptions: 1036 million

Mobiles: 1010 million

Landlines: 26 million

Total no. of PCs: 110 million

Internet users: 400 million

(Mobile internet: 159 million)

Broadband: 121 million (wired 16 million; wireless: 105 million)

\subsection{Positive Impact of ICT}

Information and Communication Technology has many positive impacts on environment. It helps us to reduce environment deterioration by providing a number of valuable benefits:

- Optimization: ICTs can help to reduce environmental impact of another product. For example using embedded systems in cars for fuel saving and using smart electricity distribution methods to reduce transmission losses. Intelligent heating and lighting systems can be used in buildings and urban environments to save energy.

- Dematerialization and substitution: Digital products can replace physical ones to lower impacts on the environment. For example, physical music and film media can be replaced with digital music and video and teleconferences can be used instead of business travel.

- ICT can help in developing and producing new technologies and materials that are sustainable and harmless for the environment.

- ICT can be used to monitor and learn about the environment to better understand it and to analyse the affects human actions on the environment.

- ICT can help to develop smarter technologies which can adjust themselves to reduce their impact on environmental. For example lights can sense and switch off automatically when nobody is in the room. 


\section{International Journal of Science and Research (IJSR) \\ ISSN (Online): 2319-7064}

Index Copernicus Value (2013): 6.14 | Impact Factor (2014): 5.611

- ICT can help the experts from all fields to share their research ideas and experience and to discover better and smarter solutions. Experts far away from each other can work together and it reduces the environmental impact caused by traveling.

- ICT provides services such as paperless communication using email and online bill payment to reduce the cut down of trees. Catalogue, telephone directories, newspapers, dictionaries also consume large quantity of paper which could be saved.

- ICT in business can reduce emissions caused by transportation of goods and the need of storage facilities for goods because it can allow production-on-demand of goods. It can help to reduce overproduction and hence reduce waste.

\section{Green Computing}

San Murugesan defined green computing in his 2008 article as "the study and practice of designing, manufacturing, using, and disposing of computers, servers, and associated subsystems for instance monitors, printers, storage devices, and networking and communications systems efficiently as well as effectively with minimum or no impact on environment."

To minimize the impact of ICT products on the environmental, its life cycle need to be managed that includes managing at three phases: the production, the use and the end-of-life. The work habits of users and business activities can be changed to minimize harmful impact on the global environment. Here are some methods that can be implemented:

\subsection{Product Longevity}

Gartner claims that the manufacturing process of a computer is responsible for $70 \%$ of the natural resources consumed in the life cycle of a computer. Fujitsu published a Life Cycle Assessment (LCA) of a desktop computer which shows that production and the end of life is liable for the majority of its ecological footprint. So, the main contribution to the green computing typically is to extend the device's lifetime. Gartner suggests to "Looking for product longevity, its upgradability and also modularity." For example, manufacturing of a new desktop computer produces a bigger ecological footprint than it is by manufacturing a new RAM module used to upgrade an existing computer.

\subsection{Data Center Design}

Facilities provided by data centers consume lot of energy which is estimated about $1.1 \%$ to $1.5 \%$ of the world's total energy consumption in 2010. The U.S. Department of Energy approximates that data center facilities utilize up to 100 to 200 times more energy than usual office buildings.

The design of energy efficient data center should consider all the aspects of the energy used in a data center. It includes IT systems, Air management, Environmental conditions, Cooling and Electrical systems etc.
Furthermore data centre wastes lot of energy in the form of heat that can be utilized well. A Switzerland Company utilizes this heat production to heat their swimming pool.

Google Inc. uses a self-styled ultra efficient evaporative cooling technology to reduce its energy consumption to $50 \%$ of that of the industry average.

\subsection{Software and Deployment Optimization}

Software controls the working of hardware and so software is very much important part of ICT. As it is said, that without proper software a PC is like a dead body. Software used to operate the hardware can be optimized to minimize the negative impacts on the environment.

\subsection{Algorithmic Efficiency}

The efficiency of algorithms has an effect on the number of computer resources needed for a computing function and there exist much efficiency in writing algorithms. By changing algorithms, such as using hashed or indexed search algorithm instead of a linear search algorithm can reduce resource consumption to a large extent. A physicist at Harvard approximated that the average Google search emitted 7 grams of carbon dioxide. Though, Google argued that a typical search emits only 0.2 grams of carbon dioxide.

\subsection{Resource Allocation}

Algorithms can be optimized to route data to those data centers which utilizes energy that is produced in a more efficient and environment friendly way. Algorithms can also be used to route traffic away from data centers that are experiencing warm weather. Those servers can be shut down to avoid the need of air conditioning.

Some factors such as locally available renewable energy, climate where outside air can be used for cooling, and locating data centers where the heat produced can be utilized, should be considered.

\subsection{Virtualization}

Virtualization allows a more cost-effective, energy efficient computing in which each server is divided into multiple virtual machines which execute separate applications. Using this approach companies can increase their server utilization. California utility PG\&E offers discounts of $\$ 300$ to $\$ 600$ for each server that companies remove using Sun or VMware virtualization products.

\subsection{Terminal Servers}

Terminal servers are also used in green computing. Terminal servers allow users at a terminal connect to a central terminal server where the processing done on the server, but the user experiences the operating system on his terminal. The terminal server with thin clients consumes up to $1 / 8$ the amount of energy of a usual workstation. It results in a decrease of energy consumption as well as costs. Two popular terminal servers software are Terminal Services for

\section{Volume 4 Issue 12, December 2015}




\section{International Journal of Science and Research (IJSR) \\ ISSN (Online): 2319-7064}

Index Copernicus Value (2013): 6.14 | Impact Factor (2014): 5.611

Windows and the Linux Terminal Server Project (LTSP) for the Linux operating system.

\subsection{Power Management}

The ACPI (Advanced Configuration and Power Interface) function is an open industry standard that allows an operating system to directly control the power-saving aspects of its hardware. The system can automatically turn off its components such as hard disks and monitors after a fixed period of inactivity. Additionally, a system may hibernate, when most components are turned off.

Software can allow user to manually alter the voltages supplied to the CPU, which reduces the amount of electricity consumed and heat production. It is called undervolting. Some systems can automatically undervolt a processor, depending on its workload. This technology is called SpeedStep on Intel, "Cool-n-Quiet" on AMD processors and LongHaul on VIA processors. Microsoft Windows provides ACPI function.

Some more points to save energy are:

- Hard disks smaller in size, consume less power than larger hard disks. Unlike hard disks flash memory or DRAM has no moving parts which reduce power consumption.

- Laptop computers use $75 \%$ less power than desktop machines.

- Monitors consume for about half of the energy consumed by a computer. Bigger the monitor, the more energy it consumes.

- LCD monitors consume only about $10-20 \%$ as much energy as CRT monitors.

- Ink jet printers consume about $90 \%$ less energy than laser printers.

\subsection{Materials Recycling}

Recycling computing devices through special methods can keep hazardous substances such as mercury, lead and hexavalent chromium out of the landfills. These components can also be reused in assembling other devices which can save energy required to make new components. Computer systems that are outdated can be donated to various nonprofit organizations and charities. Additionally, components from outdated systems can be recycled through municipal or private recycling centers. Components such as printer cartridges, batteries and paper can be recycled as well.

These schemes raised another issue that computers collected for recycling in developed countries are often shipped to developing countries with less strict environmental standards. The Silicon Valley Toxics Coalition approximates that $80 \%$ of the e-waste collected for recycling is shipped to countries such as India, Sri Lanka, and Pakistan etc.

The recycling of old computers also raises privacy issue. The storage devices in old computers hold private information, such as passwords, credit card numbers, emails and other documents that can be recovered easily. Deletion of a file does not actually remove the file from the hard drive. Before recycling a computer, the hard disk should be removed and physically destroyed.

\section{Greenwashing}

To sell their products, often companies claim that their products are environmentally safe but they really are not. It is called Greenwashing. Companies trick a customer into thinking that they are doing something because they want to help the environment. They claim that they are using less packaging to save the environment but in reality they are doing so because it will save their money. While it is better for the environment, it is not their main motivation.

Electronics companies guilty of greenwashing might sell energy-efficient electronic devices which contain harmful substances. Of course, they use less energy, but these are not truly environment friendly products. To avoid companies that greenwash, the best way is to do some homework before purchasing a device. Websites like GreenwashingIndex.com and StopGreenwash.org serve as resource centers for concerned consumers to share information.

\section{Conclusion and Suggestions}

There are two sides of the coin, if IT is facing a challenge to reduce its own carbon footprints; it also has an opportunity to help other industries to reduce their carbon footprints by introducing green solutions and technologies.

When buying computers, consumers have cared only about price and speed, instead they should care about ecological impact. New devices consume less power than older ones and renewable energy is getting more and more portable and effective. There is an alternative way to design a processor and a system such that we don't increase demands on the environment, but still provide an increased amount of processing capability to customers to satisfy their business needs. Now the time came to think about the efficient use of computers and the resources which are non-renewable.

In India, a number of e-waste recycling plants are working. They have number of e-waste collection centers across the country. For example, E-Parisaraa Pvt. Ltd. Provides enterprise solution to e-waste recycling. Instead of dumping the e-waste we should consult these types of companies for scientific recycling of e-waste.

\section{References}

[1] Vickery Graham, "Smarter and Greener? Information Technology and the Environment: Positive or negative impacts?", IISD October 2012.

[2] Sahar Javed, "Impact of Information Technology on the Environment- A Critical Analysis", Proceedings of 3rd International Conference on Business Management (ISBN: 978-969-9368-07-3)

[3] http://en.wikipedia.org/wiki/Green_computing

[4] http://www.csi-india.org/green-computing

[5] "Green IT Sustainable Information Technology (2005)", available 
http://www.greenit.net/downloads/GreenIT -EnvIssuesPCs.pdf

[6] "1 billion PC users on the way": http://news.cnet.com/Abillion-PC-users-on-the-way/2100-1003_35290988.html

[7] http://www.techno-preneur.net/informationdesk/sciencetechmagazine/2007/nov07/GreenComputing.pdf

[8] Efficient Computing http://www.google.com/corporate/datacenter/efficientcomputing/

[9] http://www.wipro.co.in/products/greenpc/html/0007clip. htm

[10] http://www.tech-faq.com/green-computing.shtml

[11] "How much electricity a computer use?": http://www.ehow.com/about_4693473_much-electricitydoes-computer-use.html

[12] http://www.ewasteindia.com 